\title{
EFFECT OF EPIPHYTES EXTRACT ON THE PEROXIDASE ACTIVITY IN THE CROP SEEDLINGS CHALLENGED WITH FUNGAL PATHOGENS
}

\author{
HAMZAH JUMAH ESSA BARKAH, LOKESH $S^{*}$
}

Department of Studies in Biotechnology, University of Mysore, Mysuru, Karnataka, India. Email: boramma@rediffmail.com

Received: 26 September 2019, Revised and Accepted: 09 November 2019

\begin{abstract}
Objectives: The objective of the present study to test the angiospermic epiphytes such as Bulbophyllum propinquum and Dendrophthoe falcata for their effect against some pathogenic fungi of sorghum, paddy and chilli, through seed treatment and foliar spray in challenging with the infectivity of the pathogens.
\end{abstract}

Methods: The plant extracts were carried out by the Soxhlet extraction method and culture of pathogenic fungi were cultured and maintained in vitro for further use. The peroxidase (POX) enzyme activity in the seedlings was measured spectrophotometrically at $300 \mathrm{~nm}$ and expressed as $\Delta$ optical density $300 \mathrm{~nm} / \mathrm{min} / \mathrm{mg}$ protein.

Results: The results of this study indicated 92 and 98\% seed germination in the control samples, respectively. In the chilli and paddy which were reduced to 64 and 58\% in seedlings inoculated with Colletotrichum dematium, Drechslera oryzae, correspondingly. Similar observation was made in sorghum samples on treatment with Fusarium solani and Fusarium oxysporum, whose germination was drastically reduced to 74 and $69 \%$ compared to control (92\%). In all the cases, seed treated with epiphytes extracts indicated the stimulated germination over pathogen inoculated samples. In parallel to this, the peroxidase assay also indicated its diminished/reduced activity in pathogen treated seedlings of the selected crop species. Seedlings of epiphytes extract treatment challenged with respective pathogens showed an increased activity over only pathogen treated samples.

Conclusion: The results clearly indicated the influence of POX in early growing stages of the seedlings corresponds to 12-72 h of incubation in spite of pathogenic activity. Thus, it proved the loss of enzyme activity seedlings on pathogen infection. Contrastingly, POX activity in the seedlings irrespective of the crop species remained high during the early growth stages of the seedlings.

Keywords: Angiospermic epiphytes, Bioactive compounds, Seed treatment, Peroxidase activity.

(C) 2020 The Authors. Published by Innovare Academic Sciences Pvt Ltd. This is an open access article under the CC BY license (http://creativecommons. org/licenses/by/4. 0/) DOI: http://dx.doi.org/10.22159/ajpcr.2020.v13i1.35884

\section{INTRODUCTION}

Among the plant species, many are known for their value as medicine and food, which are necessary for our daily life. Many plants which are medicinally important since our ancestral period are utilized to cure various ailments, including domesticated live stocks. Their valuable products are distributed as various components of the plants. Characteristically, plants' products involve phenols, saponins, flavonoids, tannins, flavonols, and other related bioactive compounds in them [1]. Plants extract irrespective of their components are being used to treat the diseased plants to protect them from bothering pathogens. Extracts of leaves, including bulbs, rhizome, bark, seeds, tender branches, and flowers and fruit of various medicinal plants are reported to have antimicrobial properties [2]. Some of them are antifungal in nature whose effect varies from species to species [3]. Many algae, lichen, and ferns are also found to be in use for the treatment of infected plants. Some of the organic as well as aqueous extract of plants proved their effectiveness in the management of plant disease-causing by altering the immune pathway. Some of the active compounds from plants are also responsible for the elicitation of systemic acquired resistance, or the resistance may also occur as a result of change in the morphological barriers in the host cells, or they may also act as stimulators of defense enzymes in response to biological stress. Considering these aspects, in the present study, epiphytic angiosperms such as Bulbophyllum propinquum Kraenzl., and Dendrophthoe falcata (L. f.) Ettingsh have been tested for their effect against pathogenic fungi of some crop species through seed treatment and foliar spray in challenging with the infectivity of the pathogens.

\section{METHODS}

To test the antifungal and plant protection activity seed of chili, paddy and sorghum were inoculated with the spore suspension of target fungi such as Colletotrichum dematium, Drechslera oryzae, Fusarium oxysporum, and Fusarium solani, respectively, in which spore suspension of each fungus was separately and freshly prepared in sterilized distilled water by suspending the 12 days speculated colonies on potato dextrose agar plates. The spore concentration was adjusted using hemocytometer to the range of $3 \times 10^{3} \mathrm{spores} / \mathrm{ml}$, using sterilized distilled water and used to soak the seed. Such inoculated 100 seeds of each crop species were sown in sterilized soil taken in the plastic trays, separately. For each test fungus, the inoculated seeds were planted in a similar manner maintained under green-house conditions in the plastic trays filled with sandy soil (1:1) and were moistened with water and incubated for further development of seedlings. Ten days of seedlings of all the crops species were further mist sprayed with epiphytic extract (100\%) for three schedules at the intervals of 3 days in the evening using a cleaned plastic mist sprayer.

On the other hand, seeds of selected crop species were soaked in the epiphyte extracts for $16 \mathrm{~h}$ at $22 \pm 2^{\circ} \mathrm{C}$ and air-dried under shade for $24 \mathrm{~h}$ on the sterilized blotters and then were sown in the plastic trays contained moistened sterilized soil maintained under green-house conditions. On the $10^{\text {th }}$ day of the growing seedlings were sprayed with the spore suspension of target fungi for three schedules for alternate days during the evening to ensure building up of humidity, which facilitated the establishment of fungi. Further, the seedlings of each treatment were separately evaluated for the occurrence of disease symptoms at every interval of 1 week. Seed treated with fungi alone, epiphytes extract alone, and with water maintained under similar conditions were considered as the respective control sets. The datum was recorded, consolidated, and tabulated in comparison with respective controls. 
Preparation of leaf extracts for the enzyme assay

Healthy leaves of 10-day-old seedlings of each treatment as mentioned above were harvested and $(0.5 \mathrm{~g})$ leaves were ground into a paste using micro-pestle with liquid nitrogen and homogenized in cold $0.05 \mathrm{M}$ sodium acetate buffer $(\mathrm{pH} 6.5)$. Then, the homogenates were centrifuged separately at $13,000 \mathrm{rpm}$ at $4^{\circ} \mathrm{C}$ for $15 \mathrm{~min}$. The supernatants of each sample were collected after centrifugation and used as crude enzyme for the analysis following the procedures as described in $[4,5]$.

\section{Analysis of peroxidase (POX)}

Two hundred microliter of $0.1 \mathrm{M}$ pyrogallol, $680 \mu \mathrm{L}$ sodium acetate buffer ( $\mathrm{pH} 6.5,0.05 \mathrm{M}$ ), and $20 \mu \mathrm{L}$ raw leaf homogenates were mixed, then $100 \mu \mathrm{L}$ of $90 \mathrm{mM} \mathrm{H} \mathrm{O}_{2}$ was added to the mixture. Immediately after adding hydrogen peroxide to the mixture, the reaction mixtures (1 ml) were used to measure spectrophotometrically (Beckman Coulter/DU ${ }^{\circledR} 730$ ) at $300 \mathrm{~nm}$. The kinetic enzyme reaction was monitored over $90 \mathrm{~s}$ and POX measurements were taken in every 10 s. Peroxidase enzyme activity was expressed as $\Delta$ optical density $300 \mathrm{~nm} / \mathrm{min} / \mathrm{mg}$ protein [4].

\section{RESULTS AND DISCUSSION}

The data represented in (Tables 1-4) indicated the variation in seed germination (SG) and disease incidence compared to control. However, disease incidence was found decreased in the treated seedlings. However, SG was found to be more in treated samples in all cases. Moreover, the seedlings growth was slightly enhanced over control, which indicated the efficacy of plant extract as a promising hypotonic, in enhancing the overall seedlings quality. The change in the SG of sorghum, chili, and paddy samples was observed on pathogen inoculated compared to control sites. Similar observation was recorded with Austroplenckia populnea on the percentage of SG, germination speed index, length of rootlets, and seedling length of Bidens pilosa L. weed [6].

In chili and paddy cultivars, initially, SG in the control was 92 and $98 \%$, respectively, which was drastically reduced to 64 and $58 \%$ on C. dematium, D. oryzae inoculation. Similarly, the mean shoot length and mean root length were also found decreased on pathogen inoculation compared to controls in chili and paddy seedlings (Tables 1 and 2).

The epiphyte extract-treated chili seedlings challenge inoculated with C. dematium, showed an increase in SG of $78 \%$, whereas untreated pathogen inoculated seed shows reduced SG (64\%). Similarly, 100\% extract of $D$. falcata plant extract decreased the disease incidence of paddy seedlings due to $D$. oryzae, comparatively. Whereas, pathogen treated seedlings exhibited SG of 58\%, which was effectively increased to $82 \%$ after extraction treatment followed by challenge inoculation.

Table 1: Influence of Dendrophthoe falcata extract on the seed germination, seedling growth and disease incidence of Colletotrichum dematium in chilli

\begin{tabular}{|c|c|c|c|c|c|}
\hline Samples & Germination* (\%) & MSL $(\mathrm{cm} \pm S E)$ & MRL $(\mathrm{cm} \pm S E)$ & VI & Disease incidence $^{* *}(\%)$ \\
\hline Control (C) & 92 & $4.9 \pm 0.3$ & $5.9 \pm 0.1$ & 993 & 0 \\
\hline Pathogen (C1) & 64 & $3.2 \pm 0.1$ & $3.9 \pm 0.8$ & 454 & 30 \\
\hline Treated $(\mathrm{T})$ & 89 & $4.9 \pm 0.4$ & $4.9 \pm 0.2$ & 872 & 12 \\
\hline Challenge inoculated (T1) & 78 & $4.5 \pm 0.2$ & $4.6 \pm 0.5$ & 733 & 18 \\
\hline
\end{tabular}

C: Samples with no pathogen and no plant extract, C1: Colletotrichum dematium inoculation, T: plant extract treatment of Dendrophthoe falcata, T1: plant extract treatment followed by pathogen. *Values are the means of four replicates of 100 seeds each. MSL: mean shoot length, MRXL: mean root length, VI: Vigor index based on four replicate of 10 seedlings each. ${ }^{* *}$ Disease incidence was recorded based on seedling death followed by the occurrence of acervuli, SE: Standard error

Table 2: Role of Dendrophthoe falcata extract on the growth stimulation and reduced disease incidence of disease in paddy due to Drechslera oryzae

\begin{tabular}{|c|c|c|c|c|c|}
\hline Samples & Germination* (\%) & MSL (cm $\pm S E)$ & MRL $(\mathrm{cm} \pm \mathrm{SE})$ & VI & Disease incidence $^{* *}(\%)$ \\
\hline Control (C) & 98 & $4.9 \pm 0.3$ & $5.9 \pm 0.2$ & 993 & 0 \\
\hline Pathogen (C1) & 58 & $3.1 \pm 0.2$ & $3.6 \pm 0.4$ & 389 & 28 \\
\hline Treated (T) & 89 & $4.9 \pm 0.2$ & $4.9 \pm 0.2$ & 872 & 20 \\
\hline Challenge inoculated (T1) & 82 & $4.4 \pm 0.5$ & $4.8 \pm 0.3$ & 757 & 22 \\
\hline
\end{tabular}

C: Samples with no pathogen and no plant extract, C1: Dendrophthoe oryzae inoculation. T: plant extract treatment of Dendrophthoe falcata, T1: plant extract treatment followed by pathogen inoculation. *Values are the means of four replicates of 100 seeds each. MSL: mean shoot length, MRL: mean root length, VI: Vigor index based on four replicate of 10 seedlings each. **Disease incidence was recorded based on seedling death and decay, SE: Standard error

Table 3: Evaluation on the efficacy Bulbophyllum propinquum extract for stimulated growth and decreased disease in sorghum

\begin{tabular}{|c|c|c|c|c|c|}
\hline Samples & Germination* (\%) & MSL $(\mathrm{cm} \pm S E)$ & MRL $(\mathrm{cm} \pm \mathrm{SE})$ & VI & Disease incidence $^{* *}(\%)$ \\
\hline Control (C) & 86 & $9.8 \pm 0.3$ & $8.6 \pm 0.7$ & 1591 & 0 \\
\hline Pathogen (C1) & 74 & $7.6 \pm 0.9$ & $6.9 \pm 0.9$ & 1073 & 28 \\
\hline Treated (T) & 82 & $8.9 \pm 0.2$ & $8.6 \pm 0.3$ & 1435 & 18 \\
\hline Challenge inoculated (T1) & 77 & $8.1 \pm 0.6$ & $7.8 \pm 0.9$ & 1257 & 20 \\
\hline
\end{tabular}

C: Samples with no pathogen and no plants extract, C1: Fusarium solani inoculation. T: plant extract treatment of Bulbophyllum propinquum, T1: plant extract treatment followed by pathogen inoculation. *Values are the means of four replicates of 100 seeds each. MSL: mean shoot length, MRL: mean root length, VI: Vigor index based on four replicate of 10 seedlings each. ${ }^{* *}$ Disease incidence was recorded based on seedling decay, SE: Standard error

Table 4: Phytostimulatory and phytoprotective activity of Bulbophyllum propinquum in sorghum against Fusarium oxysporum

\begin{tabular}{llllll}
\hline Sample & Germination* (\%) & MSL (cm \pm SE) & MRL (cm \pm SE) & VI & Disease incidence** (\%) \\
\hline Control (C) & 86 & $9.8 \pm 0.3$ & $8.6 \pm 0.7$ & 3 \\
Pathogen (C1) & 69 & $6.9 \pm 0.16$ & $6.8 \pm 0.9$ & 945 \\
Treated (T) & 82 & $8.9 \pm 0.2$ & $8.6 \pm 0.3$ & 32 \\
Challenge inoculated (T1) & 71 & $7.3 \pm 0.7$ & $7.9 \pm 0.4$ & 1435 \\
\hline
\end{tabular}

C: Samples with no pathogen and no plant extract, C1: Fusarium oxysporum inoculation. T: plant extract treatment of Bulbophyllum propinquum, T1: plant extract treatment followed by pathogen inoculation. *Values are the means of four replicates of 100 seeds each. MSL: mean shoot length, MRL: mean root length, VI: Vigor index based on four replicate of 10 seedlings each. ${ }^{* *}$ Disease incidence was recorded based on seedling decay, SE: Standard error 
The in vitro results with respect to $F$. solani and $F$. oxysporum in sorghum indicated the beneficial effect of B. propinquum. In sorghum, initially, SG in control was $92 \%$, which was drastically reduced to 74 and $69 \%$ on inoculation with $F$. solani and F. oxysporum, respectively (Tables 3 and 4).

Similarly, the mean shoot length and root length were also decreased on pathogen inoculation with respect to controls in sorghum seedlings. The vigor index of sorghum was 1591 which reduced to 1073 and 945 on pathogen inoculation with $F$. solani and F. oxysporum, respectively. On the other hand, pathogen treated seedlings exhibited SG of 74 and $69 \%$, which was increased to 77 and $71 \%$ after treatment followed by challenge inoculation with F. solani and F. oxysporum, respectively.

\section{Peroxidase activity}

The varied level POX activity was recorded in all the samples with target test fungi, and the results were represented in Figs. 1-4. In all the cases of an increase in activity was observed in treatments of epiphyte extract. The POX activity was higher in the treated samples than in the diseased as well in the healthy plants. The positive correlations were found between the increase in POX activity and disease resistance of plant tissues after infection. This suggests that POX is involved in the development of planting disease resistance. The increase in POX activity led to the production of toxic compounds which caused early killing of infected cells. The level of peroxidase is known to alter by stress, chemicals, and infections [7]. Peroxidases are also known to induce by wounding and are presumably involved in the repair of damaged cell wall.

The enzyme activity in sorghum was gradually increased on $F$. solani pathogen inoculation and also reached its peak at $60 \mathrm{~h}$ after pathogen inoculation. In pathogen inoculated, the POX enzyme activity was $5.6 \mathrm{U}$ in uninoculated control, which was significantly increased to $52 \mathrm{U}$ at $60 \mathrm{~h}$ after pathogen inoculation (hour post-inoculation [HPI]) on pathogen inoculation. Whereas, in challenge inoculated the enzyme activity was $5.6 \mathrm{U}$ in uninoculated control, which was increased to $26 \mathrm{U}$ on challenge inoculated (Fig. 1). The decrease in the POX activity was observed after treatment of plant extract followed by challenge inoculated compared to pathogen alone treated. Two-fold increase of enzyme activity was observed in plant extract treated seedlings compared to control.

Temporal pattern of POX activity in sorghum seedlings inoculated with $F$. solani, treated with $B$. propinquum indicated the variation with varied incubation period followed by challenge inoculation. The data indicated with respect to treated and control seedlings harvested at different hours after pathogen inoculation. In sorghum seedlings, gradual increase in the enzyme activity on $F$. oxysporum inoculation reached a peak at $60 \mathrm{~h}$ after pathogen inoculation (HPI). In pathogen inoculated samples, the enzyme activity was $5.6 \mathrm{U}$, in uninoculated control, it was found to be $49 \mathrm{U}$ at $60 \mathrm{HPI}$. Whereas, in challenge inoculated samples it was found to be increased 2 times more compared to the control, which was $5.6 \mathrm{U}$, reached to $16 \mathrm{U}$ compared to control.

Data represented in Fig. 2 revealed the details of enzyme activity in sorghum seedlings inoculated with $F$. oxysporum, treated with B. propinquum extract followed by challenge inoculation. Seedlings of both treatment and control harvested at different hours after pathogen inoculation showed variation in the enzyme activity, as shown in Fig. 2. The enzyme activity in paddy seedlings also reached its peak at 60 (HPI) due to pathogen inoculation. The enzyme activity was $5.6 \mathrm{U}$ in uninoculated control, which was increased to $27 \mathrm{U}$ at $72 \mathrm{HPI}$ on pathogen inoculation. Whereas, the control samples the enzyme activity changed from $5.6 \mathrm{U}$ to $27 \mathrm{U}$ in $72 \mathrm{~h}$ after inoculation (HPI). In a similar manner, in challenge inoculation sample it reached to $17 \mathrm{U}$ in hours after inoculation (HPI).

Temporal pattern of enzyme activity in paddy seedlings inoculated with $D$. oryzae, plants treated with $D$. falcata followed by challenge

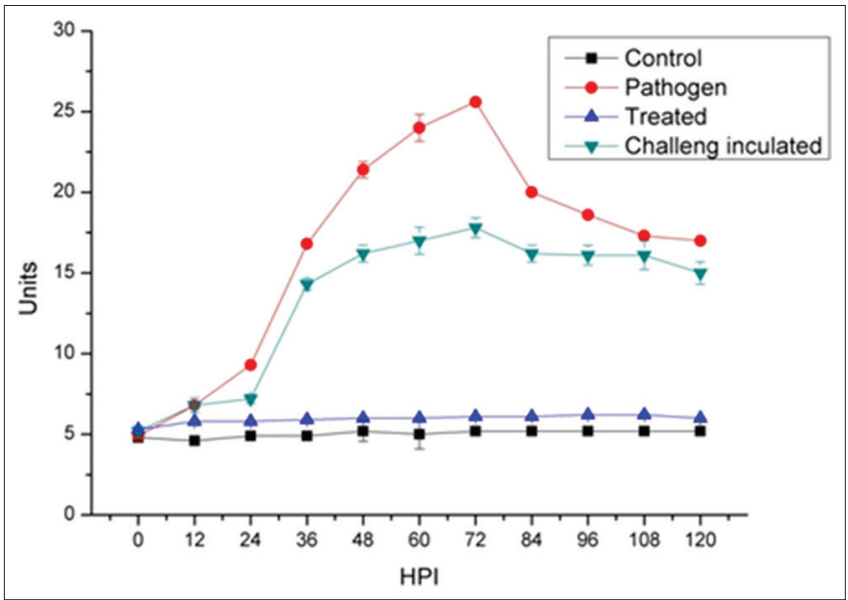

Fig. 1: Peroxidase activity in sorghum seedlings challenged with Fusarium solani

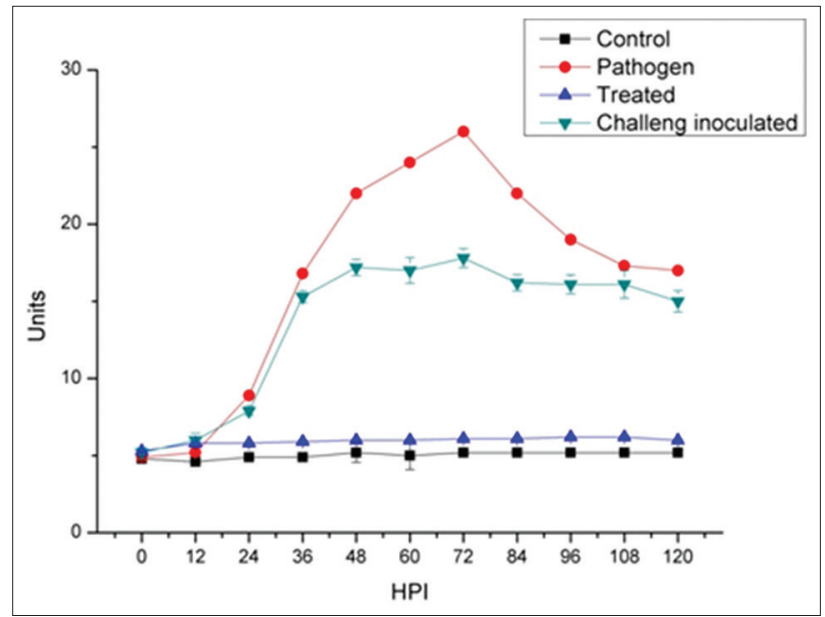

Fig. 2: Peroxidase activity in sorghum seedlings challenged with Fusarium oxysporum

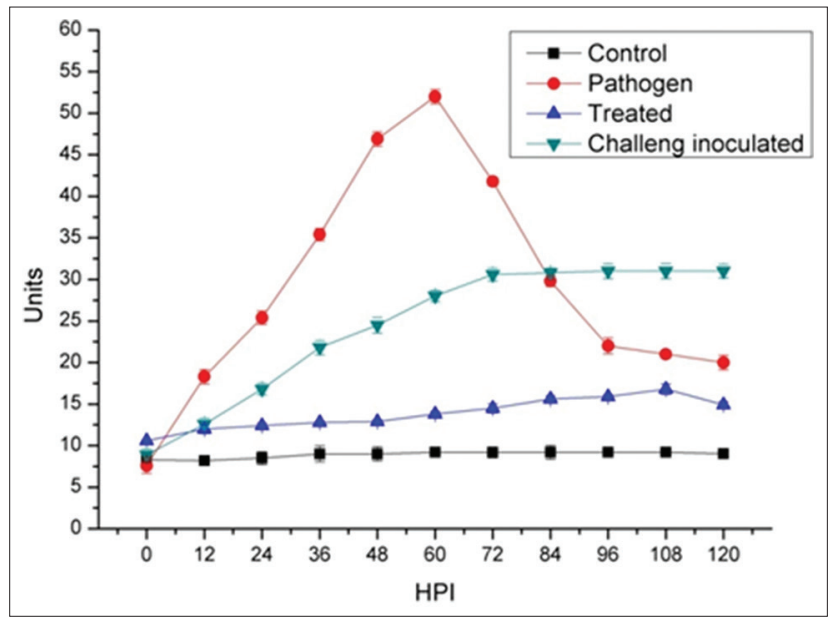

Fig. 3: Peroxidase activity in paddy seedlings challenged with Drechslera oryzae

inoculation, revealed the varied level of POX activity with varied duration incubation. Seedlings harvested from both treatment and control at different hours after pathogen inoculation and incubation indicated the variable data which were expressed as the average of triplicates. 


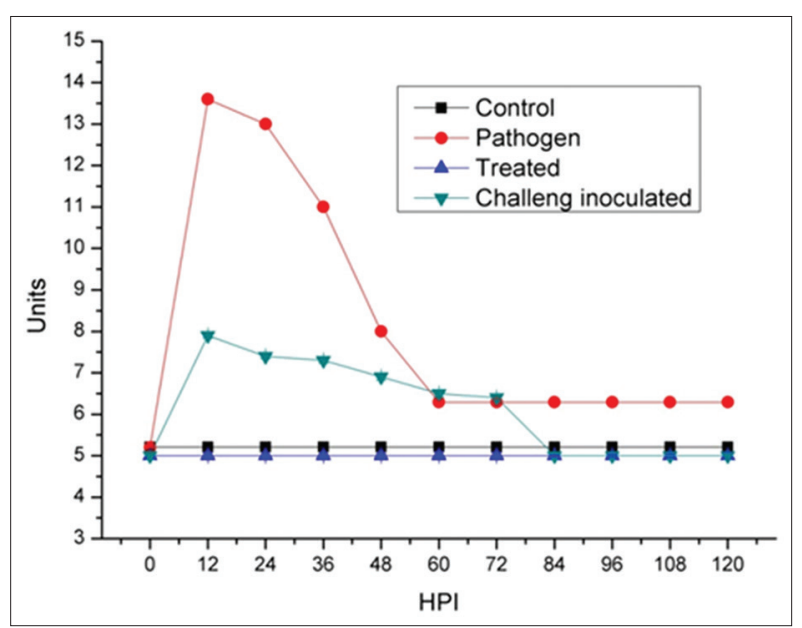

Fig. 4: Peroxidase activity in chili seedlings challenged with Colletotrichum dematium

In a similar manner, enzyme activity in chili seedlings also found to be reached a peak at $12 \mathrm{~h}$ after inoculation (HPI). In pathogen inoculated samples, the enzyme activity was $5.6 \mathrm{U}$ in uninoculated control, which was enhanced to $13.6 \mathrm{U}$ at $12 \mathrm{~h}$ after inoculation (HPI) on pathogen inoculation. Whereas, in challenge inoculated seedlings, the enzyme activity was $5.6 \mathrm{U}$ in uninoculated control, which was increased to 9.8 on challenge inoculation. Concurrently, minute variation was found in control and plant extract treated seedling, comparatively.

The data in Fig. 4 revealed that the varied enzyme activity in chili seedlings inoculated with pathogen $C$. dematium, treated with $D$. falcata followed by challenge inoculation. Both treated and control seedlings were harvested at different duration after pathogen inoculation, and the data were expressed as the average of three replicates.

The role of POXs in resistance to bacterial, fungal, and viral diseases has been extensively investigated by workers in different plants $[8,9]$. One of the most widely accepted explanations of how the phenol system and related oxidative enzymes operate in diseased plants is that, following infection of pathogens, the plant releases various phenolic compounds whose oxidation products, such as quinine, are toxic to the invading microorganisms.

Plants have many types of pre-formed phenolics and flavonoids or can increase their concentrations to defend themselves against pathogen attacks [10]. Some antioxidants (which may phenolic compounds) might enhance the enzymes activities at the site of infection or conflict and interact extracellular enzymes released by the pathogen [11]. According to earlier research observation, the selected epiphytes extract is rich in phenolic compounds [12], claims its unimportance in induction of resistance to diseases.

It is known that the phenolic compounds play a major role in plant defense to pathogens. Their presence in the treatment might have played a role in increased POX activity in the plants. Phenolic accumulation is usually occur in higher plants exhibits resistance to the pathogen. Thus, play an important role in plant defense because it oxidizes phenolic compounds into quinones that are toxic to pathogens in many respects $[13,14]$. However, the specific mechanisms responsible for having yet to be elucidated.

Overall performance with the objective of the present investigations, it has been claimed that the possible use of epiphytes extracts as antifungals at varied levels with respect to fungal species. The effectively of epiphytes in hindering the disease caused by fungi, which enhance the quality parameters instructively throw light on its ecofriendly alternative use in seed treatment. Synthetic fungicides are used for seed treatment though highly effective in plant protection against fungal diseases. Whose potency may vary depending on concentration and purity of the active principles present in it. Other possible chances may be combination of these extracts in the further purified form may serve better in enhancing the plant protection nearer to that of synthetic chemicals. The enzyme which is needed for the plants, to withstand the pathogenicity through induction of resistance directly/indirectly in situ. The pathogen in plants usually reduces the enzyme activity in the host may harbor the increased degree of susceptibility. The polyphenols, saponins, tannins, etc., as secondary metabolites present in epiphytes might involve in the plant protection through their antifungal property, hence reduced the disease incidence by which there was enhanced growth of the crop seedlings.

\section{CONCLUSION}

The present findings suggest that the selected epiphytes extracts could improve chili, paddy, and sorghum seedlings quality against the infectivity by fungal pathogens in terms of SG, seedling growth and ultimately yield of growth crop. Probably, seedlings treated with the extracts expressed the increased levels of POX activity may play a role in plant resistance to the respective fungal infection, which promises the stable field standing value of the crop, in turn, increase the economy of the grower in the eco-friendly manner.

\section{ACKNOWLEDGMENT}

Author's thanks are due to the University of Mysore, Mysuru, for providing facilities to perform the experiment in the Department of Studies in Biotechnology, Manasagangotri, Mysuru-570 006, Karnataka, India.

\section{AUTHORS' CONTRIBUTION}

Hamzah Jumah Esaa Barkah performed the experiment, calculations basic statistical analysis, and prepared the research article for its publication to throw light on researchers to utilize the natural product for plant disease management as an alternative or equivalent to synthetic fungicides. S. Lokesh has guided the whole research work and helped in the preparation of the manuscript.

\section{CONFLICTS OF INTEREST}

The authors declare that they have no conflicts of interest.

\section{REFERENCES}

1. Bennett RN, Wallsgrove RM. Secondary metabolites in plant defencemechanisms. New Phytol 1994;127:617-33.

2. Heinonen IM, Meyer AS, Frankel EN. Antioxidant activity of berry phenolics on human low-density lipoprotein and liposome oxidation. J Agric Food Chem 1998;46:4107-12.

3. Roleira FM, Tavares-da-Silva EJ, Varela CL, Costa SC, Silva T, Garrido J, et al. Plant derived and dietary phenolic antioxidants: Anticancer properties. Food Chem 2015;183:235-58.

4. Çördük N, Akınc N, Kaya N, Yücel G, Ak C. Effects of dodine on total protein content and peroxidase activity in Vicia faba. Sakarya Univ J Sci 2016;20:627-33.

5. Shah AN, Singh T, Vijayvergia RE. In vitro antioxidant properties and total phenolic and flavonoid contents of Rumex vesicarius L. Int J Pharm Pharm Sci 2015;7:81-4.

6. Caneschi CM, Souza SM, Certo TS, Souza GH, Campos MS, Duarte LP, et al. Samaras of austroplenckia Populnea (Celastraceae): New constituents and effect of extracts and friedelin on germination of Bidens pilosa (Asteraceae). Int J Pharm Pharm Sci 2014;6:318-25.

7. Gasper TH, Panel C, Hagega D, Greppin H. Biochemical, Molecular and Physiological Aspects of Plant Peroxidases. Switzerland: University de Geneva; 1991. p. 249-80

8. Birecka H, Catalfamo JL, Garraway MO. Cell wall and protoplast isoperoxidases of corn leaves in relation to cut injury and infection with Helminthosporium maydis. Plant Physiol 1975;55:607-10.

9. Jennings PH, Brannaman BL, Zscheile FP Jr. Peroxidase and polyphenol oxidase activity associated with Helminthosporium leaf spot of maize. Phytopathology 1969;59:963-7.

10. Dixon RA, Paiva NL. Stress-induced phenylpropanoid metabolism. 
Plant Cell 1995;7:1085-97.

11. Mayer AM, Staples RC. Laccase: New functions for an old enzyme. Phytochemistry 2002;60:551-65.

12. Barkah HJ, Lokesh S. Evaluation of angiospermic epiphytes for the presence of bioactive phytochemicals with special reference to phenol and tannins. J Pharm Phytochem 2018;7:164-7.
13. Mayer AM. Polyphenol oxidases in plants and fungi: Going places? A review. Phytochemistry 2006;67:2318-31.

14. Taie HA, Abd-Alla HI, Ali SA, Aly HF. Chemical composition and biological activities of two Solanum tuberosum cultivars grown in Egypt. Int J Pharm Pharm Sci 2015;7:311-20. 